\title{
UHE FOZ DO CHAPECÓ: ESTRATÉGIAS DOS AGENTES ENVOLVIDOS E O DESENVOLVIMENTO REGIONAL
}

\author{
Sadi Baron, Arlene Renk \\ Programa de Pós-Graduação em Políticas Sociais e Dinâmicas \\ Regionais, Universidade Comunitária da Região de Chapecó \\ ( UNOCHAPECÓ), Chapecó-SC
}

\section{Resumo:}

Este artigo apresenta uma reflexão sobre as estratégias adotadas pelos agentes envolvidos no processo de implantação da Usina Hidrelétrica (UHE) Foz do Chapecó, localizado no Rio Uruguai na divisa de Santa Catarina e Rio Grande do Sul. O objetivo é analisar as alianças e estratégias usadas pelos agentes envolvidos e como essas articulações ocorreram durante as diferentes fases da construção da usina e os interesses econômicos envolvidos no chamado "hidronegócio". Como esses mega empreendimentos são executados por empresas privadas com objetivos financeiros, há reflexos diretos no processo de negociação, nas formas de tratamento com a população atingida e a relação com os municípios impactados. Nesse emaranhado de pessoas e instituições envolvidas na execução de uma barragem, como a da Foz do Chapecó, é determinante ter o controle social na região. Nesse sentido foram analisadas as compensações financeiras repassadas aos municípios, os métodos adotados no processo de indenização e as articulações e estratégias usadas pelos agentes envolvidos no empreendimento. Outro fator de análise foram os efeitos em relação ao desenvolvimento da região. A construção das barragens é um espaço de disputa ideológica e um jogo de relações de poder.

Palavras-chave: hidrelétrica, movimentos sociais e desenvolvimento Regional.

\section{1 - INTRODUÇÃO}

O debate envolvendo as grandes barragens e o desenvolvimento regional é objeto de amplas discussões no mundo acadêmico e nos locais onde esses projetos são implantados. Nos municípios de implantação da UHE Foz do Chapecó, quando do anúncio e no decorrer da implantação da usina, o empreendedor divulgava que a obra traria desenvolvimento para a região, com geração de empregos, desenvolvimento econômico dos municípios e preservação ambiental. 
É importante analisar quais as medidas adotadas para minimizar os impactos da perda de áreas produtivas, a migração dos ribeirinhos, a desestruturação das comunidades, os impactos ambientais, enfim, questões que em síntese interferem no processo de desenvolvimento humano e econômico da região e suas relações políticas.

A UHE Foz de Chapecó ${ }^{1}$ é uma usina de grande porte, construída no Rio Uruguai entre Municípios de Águas de Chapecó e Alpestre, Estados de Santa Catarina e Rio Grande

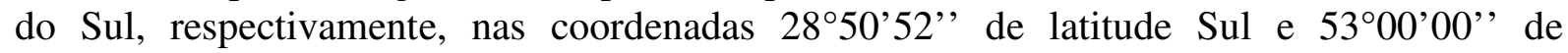
longitude com potência instalada de $855 \mathrm{MWh}$. A usina foi o primeiro empreendimento construído no Programa de Aceleração do Crescimento (PAC), com investimentos de 2,2 bilhões de reais, dos quais 1,6 bilhões de reais foram financiados pelo Banco Nacional de Desenvolvimento Social - BNDES.

A composição acionária atual do Consórcio Energético Foz do Chapecó é formada pela Companhia Paulista de Força e Luz - CPFL Geração (51\%), Furnas Centrais Elétricas (40\%) e a Companhia Estadual de Geração e Transmissão de Energia Elétrica - CEEE-GT. (9\%) A nova empresa passou a deter a concessão em 09 de agosto de 2007, quando foi assinado contrato com a ANEEL, sendo que o antigo Consórcio já a detinha desde 2002.

A usina foi o primeiro empreendimento construído no Programa de Aceleração do Crescimento (PAC), com investimentos de 2,2 bilhões de reais, dos quais 1,6 bilhões de reais foram financiados pelo Banco Nacional de Desenvolvimento Social (BNDES).

A composição acionária atual do Consórcio Energético Foz do Chapecó é formada pela Companhia Paulista de Força e Luz - CPFL Geração (51\%), Furnas Centrais Elétricas (40\%) e a Companhia Estadual de Geração e Transmissão de Energia Elétrica (CEEE-GT), (9\%). A nova empresa passou a deter a concessão em 09 de agosto de 2007, quando foi assinado contrato com a ANEEL, sendo que o antigo Consórcio já a detinha desde 2002.

A energia elétrica produzida na Usina Hidrelétrica será comercializada ou utilizada pelas Concessionárias, tendo em vista a sua condição de Produtor Independente. O Contrato de Concessão tem prazo de 35 (trinta e cinco) anos.

Grandes hidrelétricas, como UHE Foz do Chapecó, fazem parte da estratégia demandada pelo governo, dentro dos preceitos do Programa de Aceleração do Crescimento (PAC), isto é, de geração de energia voltada ao projeto nacional de "desenvolvimento econômico do país". Essas obras são objeto de conflitos, pela complexidade, que envolve impactos sociais, ambientais, mudanças impostas às populações atingidas para outras regiões. Os projetos não nascem dos anseios da população, fazendo com que se torne "atingida", por deslocamentos compulsórios, indenizações das benfeitorias e terras, consideradas justas ou não, pela perda do usufruto dos rios que servem de pesca, lazer e ponto de referência na vida dessas comunidades. Cabe, inicialmente, reconhecer que há conflitos antagônicos em relação à apropriação e outorga das águas, da necessidade ou não da obra, e dos interesses divergentes entre os atores envolvidos, direta e indiretamente, ou seja, aqueles considerados e que se consideram como atingidos.

\footnotetext{
${ }^{1}$ Os municípios atingidos, do lado catarinense, eram Águas de Chapecó, Caxambu do Sul, Guatambu, Chapecó, Paial e Itá. Do lado riograndense, Alpestre, Rio dos Índios, Nonoai, Faxinalzinho, Erval, Barra do Rio Azul, Itatiba do Sul e Faxinalzinho. Além de São Carlos e Palmitos que foram impactados com a vazão reduzida do Rio Uruguai, na jusante ${ }^{2}$ O Movimento dos Atingidos por Barragens (MAB) defende que a categoria atingida é ampla, contemplando aqueles formalmente assim considerados até aqueles que são informalmente considerados.
}

RBPD - Revista Brasileira de Planejamento e Desenvolvimento, v. 1 , n. 1, p. 114-125 , jul./dez. 2012 


\section{$\boldsymbol{R} \boldsymbol{B} \boldsymbol{P} \boldsymbol{D}$ UHE FOZ DO CHAPECÓ: ESTRATÉGIAS DOS AGENTES ENVOLVIDOS ...}

Mapa 1. Municípios atingidos pela Usina Foz Chapecó

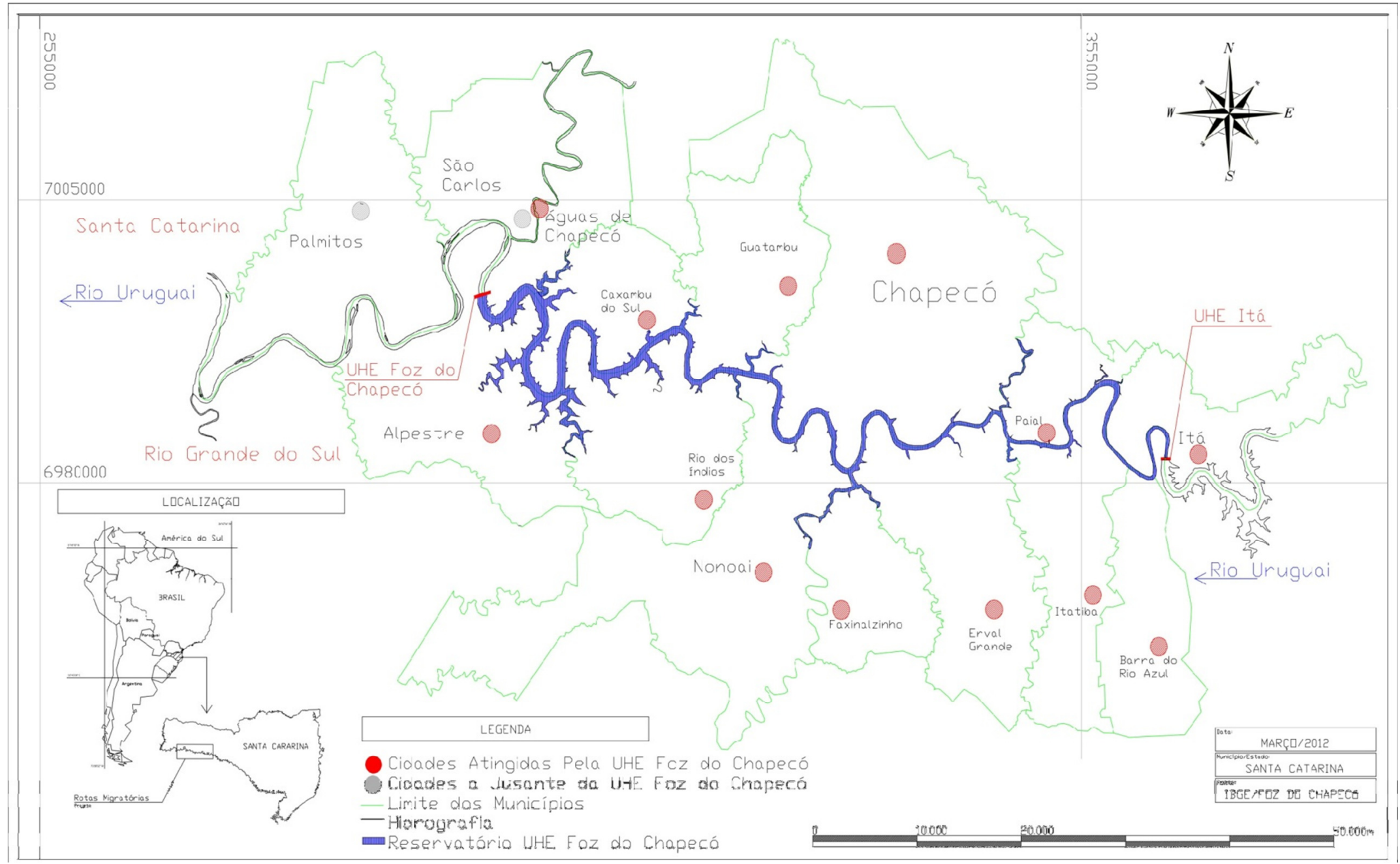

Fonte: elaborado pelo autor

RBPD - Revista Brasileira de Planejamento e Desenvolvimento, v. 1 , n. 1 , p. 114-125, jul./dez. 2012 
Com a experiência dos empreendedores em outras obras, as estratégias de controle social se aprimoraram. O que ficou explícito é que o "Empreendedor Privado" criou o interlocutor de seu controle (AMISTA). Com a criação dos Comitês municipais de negociação e a Associação AMISTA, em tese o consórcio demonstrou aos órgãos governamentais que ocorreu um processo de participação da população no processo de participação. As evidências mostram que o processo foi completamente viciado e tendencioso. O consórcio tinha completo controle sobre esses grupos com quem negociava, desde a formulação do acordo, elaborando e conduzindo todo o processo, até o auxílio financeiro que consolidou o total atrelamento e a falta de autonomia das pessoas que participavam desses espaços na tomada de decisão.

No final da década de 70 o governo federal realizou um inventário em toda a bacia do rio Uruguai, onde apontaram a possibilidade de construir 22 barragens na região (BOAMAR, 2003). Com o anúncio desse plano por parte do governo, os agricultores de toda a região iniciaram um processo de organização para defender as suas terras e sua propriedade.

\section{2 - DISCUSSÃO TEÓRICA SOBRE DESENVOLVIMENTO}

O mito do "progresso", associado às ideias de perfeição, evolução e crescimento, perpetuou-se na sociedade mundial dos séculos XVIII a XX esgotando seu ciclo com a crise de 1930. O progresso não era pensado somente no campo da ciência, mas também como melhoria de vida da população, das liberdades políticas e do bem-estar econômico. As crises econômicas e socioambientais colocaram em xeque essa visão linear do "progresso" no final do séc. 20.

Após esse período, novos paradigmas foram pensados, o desenvolvimentismo virou moda. Na América Latina o desenvolvimento econômico foi articulado pela Comissão para a América Latina e Caribe das Organizações Unidas (CEPAL), criada em 1949 onde os principais pensadores eram Raul Prebisch e Celso Furtado.

Atualmente, a noção convencional de desenvolvimento é consolidada em todo mundo. Quem se opõe a essa concepção ideológica é tachado de atrasado, que é o caso do movimento dos atingidos por barragens. Com este modelo de "desenvolvimento" onde se usa alta tecnologia, a produção em grande escala, os agricultores ribeirinhos são chamados de "atrasados". Portanto, nessa visão do que é desenvolvimento, se justifica a retirada dos mesmos para a construção das barragens e o êxodo rural é visto como algo natural, pois também já ocorreu o mesmo fenômeno nos países ditos "desenvolvidos".

Sua instalação, e a consequente formação de lagos artificiais, exigem um redimensionamento territorial, envolvendo populações humanas, em geral camponeses e indígenas, ocupantes do espaço a ser reordenado. São justamente estas populações que mantêm vínculos mais estreitos e orgânicos com a terra, que serão deslocados compulsoriamente (SCHERER; BLOEMER, 1990, p. 30). 
Apesar da constatação dos impactos negativos que o "desenvolvimento e progresso" trouxeram para a sociedade como um todo, os construtores de barragens ainda pregam que estas trarão para a região o crescimento econômico, através da geração de empregos e do turismo.

Devido aos grandes impactos causados por esse modelo descrito acima, surge um novo paradigma chamado "Modelo de Desenvolvimento Sustentável", legitimado na Eco 92 no Rio de Janeiro. Antes da Eco 92, outro documento importante foi o Relatório Brundtland (ORGANIZAÇÃO, 1997), também chamado Nosso Futuro Comum (Our Common Future). É o documento final da Comissão Mundial sobre Meio Ambiente e Desenvolvimento, promovida pela Organização das Nações Unidas (ONU), nos anos 80 e chefiada pela então primeira-ministra da Noruega, Gro Harlen Brundtland (ORGANIZAÇÃO, 1987).

Essa nova concepção tem em sua essência a visão de garantir o suprimento das necessidades das gerações futuras, usando de forma equilibrada os recursos naturais. Pressupõe um pacto econômico, social e ambiental, onde a prioridade seria atender as necessidades dos pobres, gerar uma igualdade social. Este novo modelo de desenvolvimento compreende o progresso humano em todos os seus sentidos, seja no ponto de vista cultural, econômico, social e político. (HELENE; BICUDO, 1994; ALMEIDA, 1995).

Este desenvolvimento sustentável se contrapõe ao modelo de desenvolvimento capitalista, que é extremamente predador dos recursos naturais, que construiu uma cultura consumista, padrão restrito a uma pequena parcela da população mundial.

É pertinente trazer aqui a reflexão de Antônio Carlos Diegues, que trabalha com o conceito de "Sociedades Sustentáveis". Nas populações classificadas como tradicionais, o processo do "desenvolvimento sustentável” é uma prática que faz parte da cultura.

Em relação às grandes barragens e o desenvolvimento, muitos debates e estudos ocorreram na Comissão Mundial de Barragens (CMB), atuante entre 1998 e 2000, que realizou um levantamento e avaliação das grandes barragens construídas em todos os continentes.

Uma das conclusões apresentadas no relatório final é de que as grandes barragens já construídas no mundo, mais de 45 mil, custam mais do que previstas, contribuem para o empobrecimento das populações e o processo decisório não é participativo, causando conflitos sociais. Esses conflitos sociais e ambientais segundo Rothman (2008), são agravados pela forma precária de como esses estudos são elaborados e pelo quanto são falhos no processo de possibilitar a participação das populações na tomada de decisão.

Essa nova lógica de pensar o desenvolvimento configura-se em novas redes de poder com uma forte conotação ideológica. Segundo Ribeiro (2008), essas redes de expansão econômica não são novas, como em projetos de infraestrutura econômica em Grande Escala. Desde a revolução industrial têm atuado em construção de canais, grandes usinas, etc.

Ribeiro (2008) trabalha o desenvolvimento como uma ideologia e utopia essencialmente relacionadas ao poder. Elas expressam disputas sobre interpretações do passado (ideologia) ou do futuro (utopia), e lutam para instituir hegemonia estabelecendo certas visões retrospectivas ou prospectivas como a verdade, como a ordem natural do mundo.

As questões não se limitam em ser a favor ou contra o progresso. Trata-se de projetos de vida, de autonomia e autodeterminação dos povos. Neste caso, como asseguram Vainer e Araújo no livro que trata dos "Grandes Projetos Hidroelétricos e desenvolvimento Regional", 
o desafio dos movimentos sociais consiste na resistência dos grandes projetos.

Silvio Coelho dos Santos, estudioso do tema de grandes projetos e impactos sociais, traz elementos importantes sobre a aceitação de novos conceitos por parte do Estado. Essa aceitação é resultado da pressão política exercida pelas organizações sociais nas últimas décadas.

\section{3 - HIDRONEGÓCIO}

Vainer (2008) notabilizou o uso da categoria hidronegócio, o que se constitui, a rigor, em neologismo. Essa categoria é gestada no interior das atividades hídricas, regulamentadas, e tornadas commodity, a serviço do mercado e como mais um ramo da economia de mercado. Se a água passou a ser negócio, o mercado esmera-se em diversificar os negócios. A presença do hidronegócio pode ser constatada no saneamento, abastecimento de água, esgoto, água engarrafada e, principalmente, no setor hidrelétrico. Contamos com Agência Nacional de Energia Elétrica (ANEEL) e ANA (Agência Nacional de Águas).

As grandes barragens no sul do Brasil vêm contribuindo na concentração de riquezas e transformaram os rios, as terras dos pequenos agricultores num grande negócio. Pode-se observar isso nas barragens, como as usinas de Ita, Machadinho, Barra Grande, Campos Novos, Monjolinho e Passo Fundo, Quebra Queixo, São Domingos, no rio Uruguai ou afluentes que foram construídas anteriormente à Foz do Chapecó. Segue tabela com os faturamentos das empresas que são donos das usinas na bacia do rio Uruguai.

Podemos observar que nas 07 hidroelétricas citadas no quadro abaixo, há um faturamento anual de mais de 5,7 bilhões de reais. São valores expressivos para algumas empresas, lembrando que o orçamento do Estado de Santa Catarina para 2011 é de pouco mais de 13 bilhões de reais. Temos a transformação do rio Uruguai e seus afluentes em mercadorias do "hidronegócio". Com a construção das barragens, vê-se mudanças na configuração geográfica, ambiental, sócio-cultural e, principalmente, o surgimento de novos atores políticos e econômicas de grande influência na região 
$\boldsymbol{R} \boldsymbol{B} \boldsymbol{P} \boldsymbol{D} \quad$ UHE FOZ DO CHAPECÓ: ESTRATÉGIAS DOS AGENTES ENVOLVIDOS ...

Quadro 01. Faturamento das empresas privadas nas principais usinas na Bacia do Rio Uruguai

\begin{tabular}{|c|c|c|c|c|c|}
\hline & \multirow{2}{*}{$\begin{array}{l}\text { Potência } \\
\text { (MW) }\end{array}$} & \multirow{2}{*}{$\begin{array}{l}\text { Energia Firme } \\
\text { (MW média) }\end{array}$} & \multicolumn{2}{|c|}{$\begin{array}{c}\text { Faturamento (2007) } \\
\text { Tarifa: } 258,00 / \mathrm{MW} \text { (sem Impostos) }\end{array}$} & \multirow{2}{*}{ TOTAL } \\
\hline & & & $\begin{array}{c}\text { Geração } \\
(120,00 / M W)\end{array}$ & $\begin{array}{l}\text { Distribuição } \\
(138,00 / \mathrm{MW})\end{array}$ & \\
\hline Itá & 1.450 & 720 & $\mathrm{R} \$ 746.496 .000,00$ & $\mathrm{R} \$ 858.470 .400,00$ & $\mathrm{R} \$ 858.470 .400,00$. \\
\hline Machadinho & 1.140 & 529 & $\mathrm{R} \$ 540.467 .200,00$ & $\mathrm{R} \$ 630.673 .726,00$ & $\mathrm{R} \$ 1.171 .140 .926,00$ \\
\hline Barra Grande & 690 & 380 & $\mathrm{R} \$ 393.984 .000,00$ & $\mathrm{R} \$ 453.081 .600,00$ & $\mathrm{R} \$ 847.065 .600,00$ \\
\hline Campos Novos & 880 & 378 & $\mathrm{R} \$ 391.910 .400,00$ & $\mathrm{R} \$ 450.696 .960,00$ & $\mathrm{R} \$ 842.607 .360,00$ \\
\hline Foz do Chapecó & 885 & 432 & $\mathrm{R} \$ 447.897 .600,00$ & $\mathrm{R} \$ 515.082 .240,00$ & $\mathrm{R} \$ 962.979 .840,00$ \\
\hline Passo Fundo & 220 & 119 & $\mathrm{R} \$ 123.379 .200,00$ & $\mathrm{R} \$ 141.886 .080,00$ & $\mathrm{R} \$ 265.265 .280,00$ \\
\hline Monjolinho & 67 & 43 & $\mathrm{R} \$ 44.582 .400,00$ & $\mathrm{R} \$ 51.269 .760,00$ & $\mathrm{R} \$ 95.852 .160,00$ \\
\hline TOTAL & $5.332 \mathrm{MW}$ & $2.601 \mathrm{MW}$ & $\mathrm{R} \$ 2.688 .716 .800,00$ & $\mathrm{R} \$ 3.101 .160 .766,00$ & $\mathrm{R} \$ 5.789 .877 .566,00$ \\
\hline
\end{tabular}

Fonte: ANEEL (2008). 


\section{4 - O FATOR TEMPO}

O “TEMPO" como fator de pressão e exclusão é clara quando tratamos de grandes obras. O fator "Tempo" tem um significado fundamental no processo de tomada de decisão e, consequentemente, em relação às modalidades de indenizações que os atingidos são condicionados a aceitar. Apesar de não haver muitos escritos sobre esse tema na literatura, principalmente no processo de remanejamento das populações atingidas em grandes empreendimentos, como é o caso da UHE Foz do Chapecó, esse tema deve ter uma atenção especial.

As grandes barragens, como a da Foz do Chapecó, necessitam entre o planejamento, licenciamento, negociação e o início das indenizações, períodos longos, mais de 10 anos. Esse "Tempo" de espera e de insegurança da população é vital quando da proximidade de escolha de uma modalidade. Podemos dizer que as famílias estão "cansadas" e querem definir o mais rápido possível o "rumo" a seguir. As modalidades mais rápidas são as mais adotadas, que geralmente são a indenização em dinheiro. Vejamos a diferença temporal entre as modalidades de Reassentamento Rural Coletivo (RRC), Carta de Crédito (CC) e Indenização em Dinheiro.

\section{Gráfico 01. Diferença temporal entre as modalidades de indenização (média)}

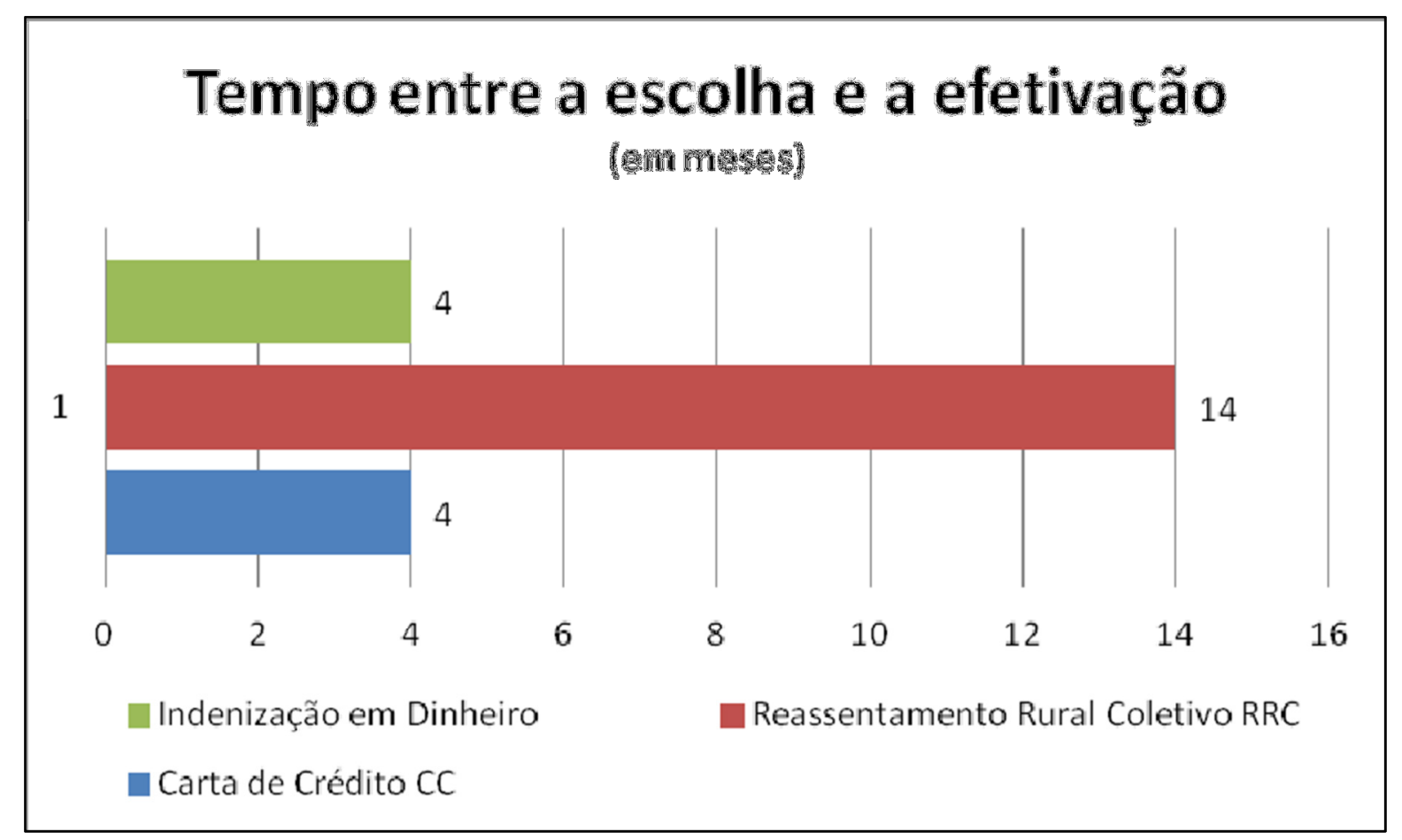

Fonte: Pesquisa de Campo (2011).

Podemos observar que a modalidade de reassentamento coletivo em grandes áreas é bem mais demorada em relação às demais modalidades. Essa constatação mostra que a pouca adesão ao RRC, tem influência direta ao fator "tempo".

Apesar da experiência positiva do ponto de vista da viabilidade social, econômica e cultural dessas famílias, cada vez menos famílias puderam ter acesso a essa modalidade. Vejamos a tabela com número de famílias reassentadas nas usinas construídas na bacia do Rio Uruguai. 
Gráfico 02. Número de famílias que optaram pela modalidade Reassentamento Rural Coletivo - RRC

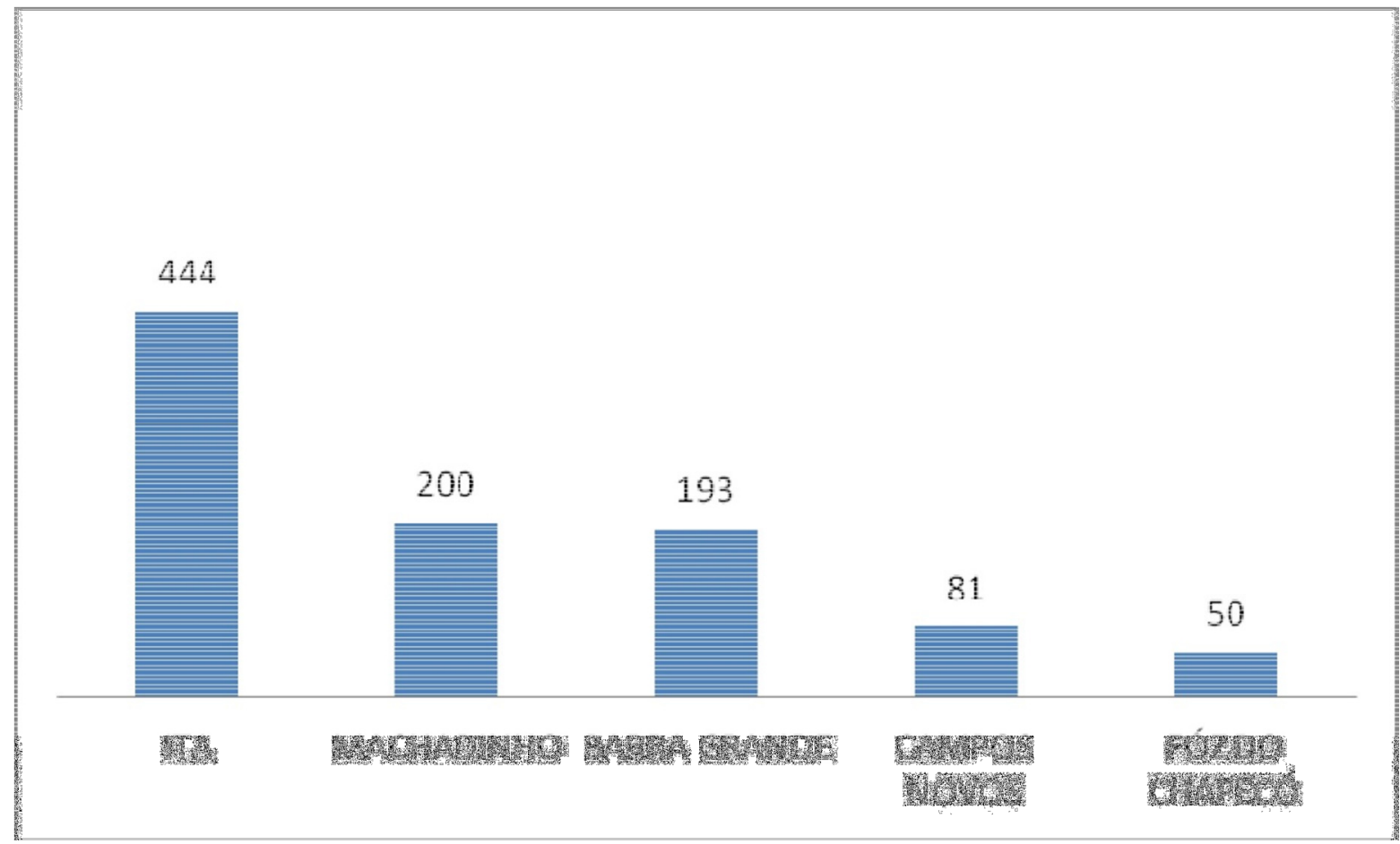

Fonte: Rocha (2011).

Podemos observar que há um processo gradativo na diminuição do número de famílias reassentadas em grandes áreas.

Para o representante do Consórcio, essa pouca adesão ao reassentamento rural coletivo em grandes áreas na Foz do Chapecó em comparação a usina de Campos Novos tem a ver com a questão cultural da região. Para a representante do governo alega que o problema da pouca adesão foi marcado pela insistência na modalidade de grandes áreas alegando que as pessoas queriam pequenos reassentamentos e também pela luta do MAB contra a barragem.

A diminuição do público para o reassentamento rural coletivo, também tem outros fatores que interferem nessas escolhas, como o crescimento econômico e o modelo de agricultura adotada, segundo Badalotti e Reis (2005). Outros fatores que poderiam ser destacados são as de ordem cultural, que extrapolam as questões econômicas como as relações comunitárias, a ajuda entre vizinhos e parentes.

Para a representante do governo o motivo de poucas famílias optarem pelo reassentamento coletivo foi devido à insistência do MAB pelos reassentamentos em grandes áreas e pela resistência na construção da obra.

Em relação ao Desenvolvimento Regional podemos observar as diferentes Visões dos Atores Envolvidos. Como esse tema está diretamente ligado a questões culturais, visões de mundo e posição social dos agentes envolvidos.

Não há como negar que os impactos negativos se refletem mais nas populações diretamente impactadas e por sua vez, nas entidades que trabalham com essas populações. A constatação é de que as obras são pensadas de fora e o processo de participação e poder de tomada de decisão das populações em entidades locais é muito baixa.

Portanto, têm pouca interferência para definir qual é o modelo de desenvolvimento a ser implantado. Ribeiro (2008) trabalha o desenvolvimento como uma ideologia e utopia 
essencialmente relacionadas a poder. Elas expressam disputas sobre interpretações do passado (ideologia) ou do futuro (utopia). A disputa de que modelo de desenvolvimento é hegemônico está relacionado às forças políticas que cada pensamento aglutina. Infelizmente, nessa região, o modelo hegemônico está ligado aos interesses do Estado e das empresas privadas.

\section{5 - CONSIDERAÇÕES FINAIS}

No caso da UHE Foz do Chapecó formou-se uma grande rede de aliança em torno da construção da usina. Na formação do consórcio, além das empresas privadas, como a Camargo Correia, Bradesco, Votarantin, estrategicamente, fez parte do consórcio uma empresa ligada ao governo federal, FURNAS. Isso fez com que grande parte dos agentes do Estado estivessem diretamente envolvidos na viabilização do empreendimento.

Por outro lado, os movimentos de resistência aglutinaram forças importantes no início do empreendimento. O Movimento dos Atingidos por Barragens (MAB), que liderava essa força de resistência, era apoiado por outros movimentos sociais, parlamentares de esquerda, Prefeituras, Setores Ambientalistas, Setores da Igreja, Sindicatos, etc.

No processo de negociação, ficou claro que havia uma estratégia do empreendedor em isolar e não legitimar o MAB, porém, no final da obra, apesar da crítica do MAB ao modelo do setor elétrico e a forma como ocorreu o processo de negociação, ocorreu uma aproximação tática do consórcio para viabilizar a implantação do reassentamento.

Em relação aos outros agentes envolvidos, como prefeituras, sindicatos, associações comerciais, associações comunitárias, etc., ocorreram diferenciações nas posições em relação ao consórcio. As posições estão muito ligadas às pautas específicas. Quando da demora ou não atendimento dos pleitos, mudava a posição ou uma maior ou menor aproximação do consórcio. As principais estratégias usadas por esses agentes são de ocupar os órgãos de comunicação para cobrar os pleitos, em alguns casos até a participação em mobilizações lideradas pelo MAB, no entanto, assim que suas pautas eram atendidas, a relação cordial com o empreendedor se reestabelecia.

Avaliando todo o processo de negociação, podemos perceber que muitas das alianças têm motivador econômico. Como o empreendedor tem a "chave do cofre", os conflitos são minimizados através do atendimento de pautas econômicas e imediatas. Justifica-se, dessa forma, os elevados recursos investidos em projetos e instituições que atuam em áreas de influência indireta da formação do lago.

Em relação às indenizações das famílias atingidas a empresa usa vários artifícios para diminuir o custo econômico e evitar a organização social dessas famílias. Constatou-se de que o fator "Tempo" é determinante no processo de escolha das modalidades. Os dados mostram que, em média, as famílias aguardavam 4 (quatro) meses para efetivar a negociação da carta de crédito e a indenização em dinheiro. Na modalidade reassentamento coletivo a efetivação do remanejamento da família demorava em média 14 (catorze) meses.

Nessa disputa ideológica na arena da UHE Foz do Chapecó, os agentes envolvidos mantiveram diferentes posições em relação ao empreendimento e o desenvolvimento da região. Apesar dos dados econômicos, ambientais e sociais não serem muito favoráveis aos municípios, perda de população, perda de áreas produtiva, perdas ambientais, baixos valores das compensações financeiras, a posição da maioria dos chefes do executivo municipais, do consórcio, do próprio governo federal, houve manifesto de que a obra trouxe desenvolvimento 
para a região. Do outro lado, os movimentos de resistência MAB, STRs, Igrejas, etc.,mantém a posição de que a barragem não beneficiou os municípios e nem a população.

Podemos perceber que, de fato como relata Ribeiro (2008), é um disputa ideológica, disputa de poder onde os agentes envolvidos a partir do seu capital social acumulado disputam na sociedade as suas posições. É incontestável a importância que a produção de energia elétrica tem para com o desenvolvimento humano, social e econômico do país. A grande questão é como esses empreendimentos interferem regionalmente.

$\mathrm{O}$ que se percebe é que as grandes obras em toda a bacia do rio Uruguai mudaram a configuração política, social e ambiental. A maioria dos municípios dessa região, têm sua economia baseada no setor agrícola, são muitas perdas de áreas produtivas, comunidades desestruturadas pela formação dos reservatórios, provocando impactos sociais e culturais irreparáveis. No aspecto ambiental, o barramento do rio, além de inundar importantes áreas às margens, gera um desequilíbrio ambiental completo na fauna, principalmente, na migração de peixes nativos que não conseguem fazer a desova no período da piracema devido aos barramentos e à qualidade da água represada.

É nesse sentido que deve haver uma ação articulada pelo Estado com uma visão regional ou por bacia hidrográfica, que venha de forma estruturada minimizar os impactos já causados. Essas ações não podem ser pontuais, imediatistas. Ter um plano de desenvolvimento regional é fundamental para poder minimizar os aspectos negativos causados na região pelos empreendimentos. Cabe, dessa forma, ao Estado, coordenar e assumir essa tarefa. Afinal, os problemas causados pelos empreendimentos, principalmente na área social e econômica, cabem as instâncias do poder público resolver, seja os municípios, estado ou a própria união. Portanto, o Estado não pode delegar à iniciativa privada, que tem por objetivos centrais o "Lucro", o papel de cuidar da questão social e o desenvolvimento regional. As ações desenvolvidas por essas empresas servem muito mais como marketing para poder se credenciar em novos empreendimentos e não pensando em sustentabilidade. $\mathrm{O}$ Estado de acordo com a legislação vigente, tem o papel de fazer compensações para a região, através de Programas de Inserção Regional, o que não isenta o Estado (nas três esferas) de avaliar, co-participar, quando for o caso, e fiscalizar estes projetos.

Os avanços sociais que ocorreram nas últimas décadas são frutos da luta social que se desencadeadas em várias frentes e setores da sociedade organizada. Apesar dos avanços muito a que fazer e avançar o fortalecimento das organizações sócias é também um passo de ampliação da democracia no país. 


\section{$\boldsymbol{R} \boldsymbol{B} \boldsymbol{P} \boldsymbol{D} \quad$ UHE FOZ dO CHAPECÓ: ESTRATÉGIAS DOS AGENTES ENVOLVIDOS ...}

\section{6 - REFERÊNCIAS}

ANEEL. Agência Nacional de Energia Elétrica. Cartilha compensação financeira. Brasília. 2007. Disponível em:

http://www.aneel.gov.br/arquivos/PDF/cartilha_compensacao_financeira_2.pdf. Acesso em: 15 mai. 2011.

BOAMAR, Paulo Fernando de Azambuja. A Implantação de Empreendimentos Hidroelétricos. O Caso da UHE Machadinho. 2003. 133 f. Dissertação (Mestrado em Engenharia de Produção) - Universidade Federal de Santa Catarina. Florianópolis (SC), 2003.

BOURDIEU, P. Da regra às estratégias. In: BOURDIEU, P. Coisas Ditas. São Paulo: Editora Brasiliense, 1990.

A gênese do conceito de habitus e de campo. In: BOURDIEU, P. O poder simbólico. 2 ed. Rio de Janeiro: Bertrand do Brasil, 1998.

CMB. Barragens e Desenvolvimento: um novo modelo de toma de decisões. 1. ed. London: Earthscan Publication Ltd, 2000.

CONSÓRCIO Energético Foz do Chapecó - CEFC. Apresentação dos Resultados na ária socioeconômico da UHE Foz do Chapecó, Chapecó (SC), 2010. (slides)

ENGEVIX. Relatório de Impacto Ambiental - RIMA. UHE Foz do Chapecó. Chapecó (SC), p. $66,2000$.

DIEGUES, Antônio Carlos, O mito moderno da natureza intocada. São Paulo: Hucitec, 1998.

HELENE, Maria Elisa Marcondes; BICUDO, Marcelo Briza. Sociedades Sustentáveis. São Paulo: Scipione, 1994.

MME. Ministério de Minas e Energia. Site Oficial. mai. 2007. Disponível em: http://www.mme.gov.br. Disponível em: 20 mai. 2011.

ONU - Organização das Nações Unidas. Relatório de Brundtlland, Nosso Futuro Comum (Our Common Future), Genebra, Suíça - 1997.

REIS, Maria José. O Movimento dos Atingidos por Barragens: atores, estratégias de luta e conquistas. Florianópolis: UFSC/UNIVALI, 2001.

RIBEIRO, Gustavo Lins. Poder, redes e ideologia no campo do desenvolvimento. Novos Estudos (CEBRAP), São Paulo, n. 80, mar. 2008.

ROCHA, Humberto José. Configuração social e suas implicações na negociação para a instalação da UHE Foz do Chapecó. In: Reunião de Antropologia do Mercosul, 9, Curitiba (PR), jul. 2011.

SCHERER, Warren Ilse; REIS, M.J. O Movimento dos Atingidos pelas Barragens do Uruguai: universidade e diversidade. Caderno do Ceas, Salvador, n. 120, mar./abr., 1989.

SCHERER, Warren Ilse; REIS, M.J.; BLOEMER, N, M. Alto Uruguai: migração forçada e reatualização da identidade Camponesa. Revista Travessia, São Paulo, SP. Centro de Estudos migratórios (CEM), ano II, n. 6, jan./abr. 1990.

VAINER, Carlos B.; ARAÚJO, Frederico Guilherme B. de. Grandes Projetos Hidroelétricos e desenvolvimento regional. Rio de Janeiro (RJ): Cedi - Centro Ecumênico de Documentação e Informação, 1992.

WORLD COMMISSION ON DAMS. Dams and Development: a new framework for decision making. London: Earthscan, 2000. 